\title{
A Comparative Randomise Study of Chemotherapy versus Chemoradiation in Unresectable Locally Advanced Gallbladder Carcinoma
}

\author{
Authors \\ Dr Kamlesh Kumar Harsh ${ }^{1}$, Dr Satya Narayan ${ }^{2}$, Dr Sitaram Maharia ${ }^{2}$, \\ Dr Rajkumar Nirwan ${ }^{2}$, Dr SL Jakhar ${ }^{3}$, Dr Neeti Sharma ${ }^{4}$, Dr HS Kumar \\ ${ }^{1}$ Junior Specialist, ${ }^{2}$ Medical Officer, ${ }^{3}$ Assistant Professor, ${ }^{4}$ Associate Professor, ${ }^{5}$ Senior Professor and HOD, \\ Department of Radiation Oncology, Acharya Tulsi Regional Cancer Treatment and Research Institute, \\ Bikaner, Rajasthan \\ Corresponding Author \\ Dr Kamlesh Kumar Harsh \\ Junior Specialist, Department of Radiation Oncology, Acharya Tulsi Regional Cancer Treatment and \\ Research Institute, Bikaner, Rajasthan \\ Email:dr.kamleshharsh@gmail.com
}

\section{INTRODUCTION}

Gall bladder (GB) carcinoma is most common biliary tract malignancy worldwide. (1) The incidence is increasing globally and also in India. Recently, the Indian Council of medical research (ICMR) has reported that incidence rates of GB cancer in women in Northern India (more than 9 per 100000 per year) are one of the highest in the world. Cholelithiasis is frequently associated with GB cancer in up to $40 \%-90 \%$ patients and is the most common associated factor independent of age or sex. (2) Surgery is potentially curative treatment in early stage of GB cancer. But vague presenting symptoms often delay the diagnosis of GB cancer, thus contributing to its overall progression and poor outcome. Overall mean survival is six months, while 5- year survival rate is only 5\%. ${ }^{(3)}$ Palliative therapy is the treatment which alleviates the distressing symptoms caused by advanced cancer. Palliative chemotherapy or radiotherapy helps to improve quality of life, reduces risk of complications and also has some survival benefit. In an effort to improve survival rates and quality of life, neoadjuvant or concurrent chemotherapy has been used. Radiation therapy is safe and tolerable as palliative therapy in unresectable GB cancer to relieve symptoms like abdominal pain and obstructive jaundice. It acts by shrinking tumors that are blocking passage ways for blood or bile or are pressing on nerves. (4)

The goal of the study was to evaluate the efficacy and safety of chemotherapy alone as Gemcitabine and Cisplatin versus continuous daily Capecitabine with radiotherapy in patients with previously untreated locally advanced unresectable GB carcinoma. The primary end point was radiologic response and symptomatic evaluation. The secondary end point included overall survival and tolerability. 


\section{MATERIAL AND METHODS}

One hundred histologically conformed untreated patients of adenocarcinoma of GB were randomly enrolled for study from $1^{\text {st }}$ September 2013 to $31^{\text {st }}$ August 2014, out of 224 patients total enrolled during one year. Staging was done as per TNMStaging system. Routine hematological and radiological investigations were done before starting the treatment. The mean age of patients was 52 years (range 30-75years). The Table no-1 describes the baseline characteristics.

\section{CONTROL GROUP}

Control group patients were treated with chemotherapy only, in form of Gemcitabine (1000 $\mathrm{mg} / \mathrm{m}^{2} /$ day on day 1 and day 8 ) and Cisplatin (75 $\mathrm{mg} / \mathrm{m}^{2}$ ) for total 6 cycles each cycle given after 21 days.

\section{STUDY GROUP}

Study group patients were treated with external beam radiotherapy, 2.0 Gy per fraction, 5 days per week for 5 weeks, total 22 fractions to a total dose of $44 \mathrm{~Gy}$ followed by a boost of 3 fraction of 2.0 Gy each to the tumor bed and regional lymph nodes. Total dose was 50.0Gy. Concurrent chemotherapy was administered in form of oral Capecitabine. Capecitabine was administered at planned escalating doses of $1000-1,250 \mathrm{mg} / \mathrm{m} 2$ B.D. The first daily dose was given 2 hours before radiation therapy and second dose was given 12 hr. after the first dose, and followed by Capecitabine monotherapy 3 weekly, one week rest,continue for 6 cycles.

\section{RADIOTHERAPY}

Tumor bed was marked using ultrasonography. EBRT was delivered to the tumor bed and lymphatics through parallel opposed anterior and posterior portals using cobalt-60 gamma rays. The field included tumor bed, porta-hepatic, pancreatico-duodenal nodes, celiac nodes and retroperitoneal nodes. Blocks were used to exclude stomach, small-intestine, kidney and liver. The primary goal was to optimize loco- regional control. The overall treatment time of radiotherapy was approximately 6 weeks. Study group patients were monitored weekly during radiation treatment and thereafter, every 3 weeks during treatment with Capecitabine monotherapy and then patients were followed up every 3 months. Physical examination, routine hematological tests and radiological examinations were done as per the standard schedule. Response evaluation was done using response evaluation criteria in solid tumors (RECIST-Criteria). The median follow up time was 2 years. Information concerning disease status, complications and death was available through follow up, institutional records, letters and telephonic contact directly with the patients or relatives.

\section{STATISTICAL ANALYSIS}

Symptomatic and radiological response rates of disease were calculated after the one month of treatment and then patients were followed up every 3 months up to 2 years. Signs, symptoms and adverse events during treatment were recorded from the date of initiation of treatment to the last follow up. Overall survival was estimated by Kaplan-meier method. For statistical analysis, data was arranged using SPSS 21 version. Toxicity was assessed by using the RTOGcriteria.

\section{RESULTS}

One hundred patients were randomized from $1^{\text {st }}$ September 2013 to $31^{\text {st }}$ August 2014, out of which 50 patients each in control (chemotherapy) and study (chemo-radiation) groups were assessable for efficacy and safety. The median follow up was 8.5 months (range 0.8-24 months).The results were calculated from the date of initiation of treatment to the occurrence of any event or death.

\section{DISEASE RESPONSE TO TREATMENT}

After three month of the completion of treatment, according to the RECIST-criteria, objective response (complete + partial response) was attained in $34(68.0 \%)$ and $28(56.0 \%)$ patients, in 
the study group and control group, respectively (Table- 2). Stable disease was observed in 5 (10.0 $\%)$ and $6(12.0 \%)$ patients in study and control group, respectively and progressive disease in 4 $(8.0 \%)$ and $6(12.0 \%)$ patients in study and control group, respectively. 7 (14.0\%) and 8 (16.0 $\%$ ) patients of study and control group respectively, expired at the end of three months follow up. At the end of 2 years, objective response (complete + partial response) was observed in $6(12.0 \%)$ patients in study group and $2(4.0 \%)$ patients in control group. There are 43 $(86.0 \%)$ patients in study group and $46(92.0 \%)$ patients in control group who expired.

\section{OVERALL SURVIVAL}

Patients who were treated by chemo-radiation (study group) has a improvement in overall median survival (7.5 months) compared with chemotherapy alone (control group) 5.8 months $(\mathrm{P}<0.05)$. The two years overall survival rate of control group was $8.0 \%$ and study group was 14 $\%$. Patients died due to systemic and locally progressive disease. Among study group 43 (86.0\%) and control group 46(92.0\%) patients died at the end of 2 years follow up.

\section{SYMPTOMATIC BENEFIT}

Significant symptomatic benefit can be achieved with relief of biliary obstruction (relieves puritus and hepatic dysfunction). After chemotherapy 20 $\%$ and chemoradiation $25 \%$ patient didnot need percutaneous transhepatic cholangiography (PTC), drainage endoscopic retrograde cholangiopancreatography (ERCP) guided stenting or surgical bypass. Local response rate which reflected the reopening of occluded bile duct was $74 \%$ in control group and $82 \%$ in study group. Abdominal pain was relieved in $55 \%$ cases. Nausea and vomiting were relieved initially but increased after using chemotherapy. No change in feeling of abdominal lump by patients. Overall 60 $\%$ patients showed symptomatic relief for a mean duration of $4.7 \pm 3.5$ months. Recurrence developed in $12(66.7 \%)$ patients in a period of two years of follow up. Metastasis occurred in 48 cases, in which 24 metastasized to liver, 8 to lungs, 3 to ovaries, 4 to supraclavicular lymph nodes (left), 7 to peritoneum and 2 to bones.

\section{COMPLICATIONS AND REACTIONS}

In the study three patients develops hemetemesis due to duodenal perforation. Two patients had stricture developed at the junction of first part of duodenum and pylorus in study chemoradiation group. In 18 cases, recurrent ascites with repeated tapping leaded to shock and death. Fever persisted in 8 cases and led to death due to severe infection. Grade 3 Hand-Foot Syndrome (HFS) develop in 6 $\%(n=3)$ after 6 weeks at dose level of $>1,000$ $\mathrm{mg} / \mathrm{m} 2 \quad$ B.D./day and 1 (2\%) cases develops grade- 3 reactions during $6^{\text {th }}$ cycle of Capecitabine monotherapy. Chemotherapy and concurrent chemo-radiation led to development of anorexia (grade-3 \& 4) in $35 \%$ cases, stomatitis (grade-3) in $12 \%$ cases. Adverse events according to Maximum National Cancer Institute Common Toxicity Criteria are as follows, Nausea (grade-3 in 4\%), Vomiting (grade-3 in 6\%), Diarrhea in (grade-3 in 2\%), grade-2 fatigue develops in $10 \%$ cases when dose level $>1,000 \mathrm{mg} / \mathrm{m} 2$ B.D. of Capecitabine. Dose reductions were done after grade-2 and grade-3 toxicity. Treatment interrupted and treat all cases symptomatically and when the toxicity resolved treatment was continue without dose adjustment.. WHO- grade 3 and 4 febrile neutropenia developed in $8 \%$ cases, $12 \%$ cases needed blood transfusion for anaemia grade 3 and 4 whereas grade 3 and 4 thrombocytopenia was seen in $10 \%$ cases. The toxicity management was according to standard guidelines. 


\section{JMSCR Vol||05||Issue||01||Pages 16058-16064||January}

Table No.1 Baseline characteristics of the patients

\begin{tabular}{|c|c|c|c|c|c|}
\hline \multirow{2}{*}{\multicolumn{2}{|c|}{ Characteristics }} & \multicolumn{4}{|c|}{ Observation } \\
\hline & & \multirow{2}{*}{$\begin{array}{c}\begin{array}{c}\text { Study Group } \\
\mathbf{n = 5 0}\end{array} \\
34 \\
\end{array}$} & \multirow{2}{*}{$\begin{array}{c}\% \\
68.0\end{array}$} & \multirow{2}{*}{$\begin{array}{c}\begin{array}{c}\text { Control } \\
\text { Group } \mathbf{n}=\mathbf{5 0}\end{array} \\
36\end{array}$} & \multirow{2}{*}{$\begin{array}{c}\% \\
72.0\end{array}$} \\
\hline Background & Rural & & & & \\
\hline & Urban & 16 & 32.0 & 14 & 28.0 \\
\hline \multirow[t]{2}{*}{ Age } & $30-50 \mathrm{yr}$ & 22 & 44.0 & 21 & 42.0 \\
\hline & $51-75 \mathrm{yr}$ & 28 & 56.0 & 29 & 58.0 \\
\hline \multirow[t]{3}{*}{ Gender } & Male & 18 & 36.0 & 17 & 34.0 \\
\hline & Female & 32 & 64.0 & 33 & 66.0 \\
\hline & 70 & 14 & 28.0 & 13 & 26.0 \\
\hline \multirow[t]{2}{*}{ KPS Score } & 80 & 31 & 62.0 & 30 & 60.0 \\
\hline & 90 & 5 & 10.0 & 7 & 14.0 \\
\hline \multirow{7}{*}{$\begin{array}{l}\text { Sign } \\
\text { and } \\
\text { Symptoms }\end{array}$} & Jaundice & 32 & 64.0 & 29 & 58.0 \\
\hline & Abdominal pain & 28 & 56.0 & 29 & 58.0 \\
\hline & Ascites & 4 & 8.0 & 6 & 121.0 \\
\hline & Fever & 3 & 6.0 & 5 & 10.0 \\
\hline & Nausea & 25 & 50.0 & 22 & 44.0 \\
\hline & Vomiting & 18 & 36.0 & 20 & 40.0 \\
\hline & Palpable mass & 16 & 32.0 & 21 & 42.0 \\
\hline \multirow{2}{*}{$\begin{array}{l}\text { Incidence of Gall } \\
\text { stone }\end{array}$} & present & 44 & 88.0 & 46 & 92.0 \\
\hline & Absent & 6 & 12.0 & 4 & 8.0 \\
\hline \multirow{3}{*}{ Stage TNM } & III-A (T ${ }_{3}$ N.M.) & 14 & 28.0 & 16 & 32.0 \\
\hline & III-B ( $\left.\mathrm{T}_{2} \mathrm{~N}_{1} \mathrm{M}.\right)$ & 24 & 48.0 & 26 & 52.0 \\
\hline & IV-A ( $\left.\mathrm{T}_{4} \mathrm{~N}_{01} \mathrm{M}.\right)$ & 12 & 24.0 & 8 & 16.0 \\
\hline \multirow{3}{*}{$\begin{array}{l}\text { Histopathology } \\
\text { Adenocarcinoma }\end{array}$} & Well differentiated & 16 & 32.0 & 14 & 28.0 \\
\hline & Moderately & 24 & 48.0 & 23 & 46.0 \\
\hline & Poorly/ Undifferentiated & 10 & 20.0 & 13 & 26.0 \\
\hline
\end{tabular}

Table No.2 Disease - Status

\section{(According to RECIST - Criteria)}

\begin{tabular}{|c|c|c|c|c|c|c|c|c|c|c|c|c|c|c|}
\hline \multirow[t]{2}{*}{ S.N. } & \multirow{2}{*}{$\begin{array}{l}\text { Disease } \\
\text { Status }\end{array}$} & \multirow[t]{2}{*}{ Group } & \multicolumn{12}{|c|}{ Follow up at } \\
\hline & & & $\begin{array}{l}3 \\
\text { Month }\end{array}$ & $\%$ & $\begin{array}{l}6 \\
\text { Month }\end{array}$ & $\%$ & $\begin{array}{l}9 \\
\text { Month }\end{array}$ & $\%$ & $\begin{array}{l}12 \\
\text { Month }\end{array}$ & $\%$ & $\begin{array}{l}18 \\
\text { Month }\end{array}$ & $\%$ & $\begin{array}{l}24 \\
\text { Month }\end{array}$ & $\%$ \\
\hline \multirow[b]{2}{*}{1} & \multirow{2}{*}{$\begin{array}{l}\text { Complete } \\
\text { Response }\end{array}$} & Study & 10 & 20.0 & 10 & 20.0 & 7 & 14.0 & 6 & 12.0 & 4 & 8.0 & 4 & 8.0 \\
\hline & & Control & 8 & 16.0 & 7 & 14.0 & 6 & 12.0 & 6 & 12.0 & 4 & 8.0 & 2 & 4.0 \\
\hline \multirow[b]{2}{*}{2} & \multirow{2}{*}{$\begin{array}{l}\text { Partial } \\
\text { Response }\end{array}$} & Study & 24 & 48.0 & 18 & 36.0 & 9 & 18.0 & 5 & 10.0 & 2 & 4.0 & 2 & 4.0 \\
\hline & & Control & 20 & 40.0 & 16 & 32.0 & 8 & 16.0 & 3 & 6.0 & 0 & 0.0 & 0 & 0 \\
\hline \multirow[b]{2}{*}{3} & \multirow{2}{*}{$\begin{array}{l}\text { Stable } \\
\text { Disease }\end{array}$} & Study & 5 & 10.0 & 4 & 8.0 & 3 & 6.0 & 3 & 6.0 & 1 & 2.0 & 0 & 0 \\
\hline & & Control & 6 & 12.0 & 5 & 10.0 & 3 & 6.0 & 0 & 0 & 0 & 0.0 & 0 & 0 \\
\hline \multirow[b]{2}{*}{4} & \multirow{2}{*}{$\begin{array}{l}\text { Progressive } \\
\text { Disease }\end{array}$} & Study & 4 & 8.0 & 2 & 4.0 & 5 & 10.0 & 4 & 8.0 & 4 & 8.0 & 1 & 2.0 \\
\hline & & Control & 8 & 16.0 & 5 & 10.0 & 4 & 8.0 & 6 & 12.0 & 5 & 10.0 & 2 & 4.0 \\
\hline \multirow[b]{2}{*}{5} & \multirow[b]{2}{*}{ Total Death } & Study & 7 & 14.0 & 16 & 32.0 & 26 & 52.0 & 32 & 64.0 & 39 & 78.0 & 43 & 86.0 \\
\hline & & Control & 8 & 16.0 & 17 & 34.0 & 29 & 58.0 & 35 & 70.0 & 41 & 82.0 & 46 & 92.0 \\
\hline
\end{tabular}

\section{DISCUSSION}

Historically, GB carcinoma has carried a dismal prognosis. Approximately 70 to $80 \%$ of patients present in stage III and IV. ${ }^{(7)}$ This has been attributed to the late presentation of patients and the technical difficulty of an adequate surgical resection in the presence of advanced local and regional involvement. There has been an improvement in the modern imaging techniques but still GB carcinoma is diagnosed late due to its vague symptoms. More effective therapies have emerged with improvement in the survival of patients with invasive cancer ${ }^{(4)}$.

The location, size, extension and stage at presentation of the tumor are important for determining prognosis. Larger tumors are less likely to respond to radiotherapy because their poor vascular supply reduces radiosensitivity. Concurrent chemotherepy leads to radiation sensitization, secondary to synergistic DNA damage, cell cycle synchronization and inhibition of repair and resistance pathways. Chemotherapy 
alone or with radiation improves local tumor control, reduces micrometastases and decreases the risk of distant metastasis ${ }^{(1)}$. Sixty percent of patients of study group were free from distressing symptoms of abdominal pain and obstructive jaundice. With improvement in nutrition, there was significant weight gain after treatment ${ }^{(5)}$.

Treatment of unresectable locally advanced GB carcinoma usually consists of various palliative strategies which provide only a modest survival benefit ${ }^{(5)}$. Mostly patients received 5-Flourouracil based chemotherapy so we also tried. Capecitabine is a oral prodrug converted in 5-FU and works as radiosensitizer if it is taken at least 2 hours prior to irradiation ${ }^{(5)}$. Gemcitabine has excellent clinical activity against solid tumors. Gemcitabine-based combination chemotherapy is widely accepted with gemcitabine and cisplatin combination chemotherapy as one of the most commonly used regimens ${ }^{(8)}$. Exposure to normal tissues to 5-FU within the radiation field is likely to be lower with oral Capecitabine compared with intravenous 5-FU. Capecitabine-based chemoradiation may have enhanced therapeutic ratio compared with 5-FU based treatment in patients. Capecitabine also avoids the potential complications associated with indwelling central venous catheters, such as infections, sepsis, thrombosis and blockage. Chemotherapy and concurrent chemo-radiation provide immediate symptomatic relief by arresting growth, shrinkage of tumor, decreasing risk for loco-regional failure and hence improving survival. In recent years, several groups have reported that chemotherapy and concurrent chemo-radiation improves the survival and symptomatic relief.

In case of chemotherapy alone, Malik et al showed that gemcitabine and cisplatin chemotherapy had $9 \%$ complete response, $55 \%$ partial response and $64 \%$ overall response rate. Median overall survival was 42 weeks ${ }^{(8)}$. Shewach et al showed that in gemcitabine and cisplatin combination chemotherapy $9.5 \%$ cases showed complete response and $38.09 \%$ showed partial response. The median survival time was 7 months and toxicity was reasonable ${ }^{(9)}$. Doval et al showed $13.3 \%$ complete response, $23.3 \%$ partial response, $23.3 \%$ stable disease and $13.2 \%$ progressive disease. The median time to progression was 18 weeks and median overall survival was 20 weeks. One year survival rate was $18.6 \%$. Gemcitabine and cisplatin combination is well tolerated ${ }^{(10)}$. In our study 2 year survival rate were $8.0 \%$ and chemotherapy is well tolerated. Yamashita et al showed that $33.3 \%$ cases show partial responses, $57.2 \%$ show stable disease and $9.5 \%$ complete response. The median overall survival time was 18.8 months and median time to progression was 13.4 months ${ }^{(11)}$. In our study objective response (complete + partial response) $28(56.0 \%)$ was observed and overall median survival 5.8 months Stable disease was observed in $6(12.0 \%)$ patients and progressive disease in $6(12.0 \%)$ patients. Overall $52 \%$ patients showed symptomatic relief for a mean duration of $4.9 \pm 3.1$ months. Recurrence developed in $6(30 \%)$ patients in a period of two years of follow up. And in case of chemo-radiation Singh et al showed that oral capecitabine regimen has shown the best survival benefit in chemoradiation in unresectable GB carcinoma. The mean survival was 2.6 years whereas other regimens had mean survival of 8 to 16 months and those who received only best supportive care had mean survival of 3.6 months ${ }^{(12)}$. Kapoor et al showed that patients on combined chemotherapy and radiotherapy had better 2-years disease free survival (DFS) of $60 \%$ as compared to those who did receive single modality of treatment. Liver infiltration by tumor was found to be a bad prognostic factor with DFS at one year of 0.8 vs 0.5 patients with no liver infiltration $(\mathrm{P}=0.06){ }^{(7)}$. Park et al showed that local response rate (reopening of occluded bile duct) was $89.5 \%$. 36.6\% showed overall response. Longest survival time was 52 months and median survival time was 14 months. One and two year survival rates were $82.2 \%$ and $31.6 \%$ respectively (13). In our study $32.0 \%$ cases reopen the occluded bile duct. Engineer et al showed that complete metabolic and radiological response was observed 
in $66.6 \%$ and partial response i $33.4 \%$. Median overall survival was 20 weeks ${ }^{(4)}$. Gallardo et al reported the results of a series of 26 patients with metastatic and unresectable GB carcinoma. He observed a $36 \%$ response rate and 30 months of median survival $^{(14)}$.

Capecitabine, an orally administered systemic 5fluorouracil prodrug, has been tested in GB carcinoma. One of the main positive effects of this drug is its capacity to lead to 5FU concentrations in tumors 125 times greater than serum concentrations. The effect of capecitabine on GB carcinoma was evaluated by Patt Y, who showed a $50 \%$ response rate and median overall survival of 10.1 weeks ${ }^{(15)}$. Knox et al reported combination of gemcitabine and capecitabine showing overall objective response rate of $31 \%, 42 \%$ patients had stable disease and disease control rate of $73 \%$. The median overall survival time was 14 months and median progression-free survival time was 7 months. Tolerance was good even in patients with liver dysfunction or biliary stents. Median overall survival was 14 weeks ${ }^{(16)}$. In our study objective response (complete + partial response) 34(68.0\%) was observed and overall median survival 7.5 months Stable disease was observed in $5(10.0 \%)$ patients and progressive disease in $4(8.0 \%)$ patients. Overall $68 \%$ patients showed symptomatic relief for a mean duration of $5.6 \pm$ 3.8 months. Recurrence developed in $6(30 \%)$ patients in a period of two years of follow up.

\section{CONCLUSION}

GB cancer remains a lethal malignancy. In this study chemo-radiation had overall survival, symptom free rates and local control rates similar to those reported in literature but better than chemotherapy alone in patients with stage III or IV disease. This study reports a single institution experience of using chemotherapy alone or with radiation in patients with GB carcinoma (stage IIIA, III-B \& IV-A), which gave better symptomatic relief and was well tolerated. Gemcitabine, cisplatin and capecitabine are effective as adjuvant therapy in carcinoma GB to improve treatment outcome. Both chemotherapy and radiotherapy have superior survival outcomes. Improvements in treatment are still required. Unique method but still under investigational process and larger randomized trials are needed to verify these good results.

\section{REFERANCES}

1. Zhu AX, Hong TS, Hezel AE, Kooby DA. Current management of gallbladder carcinoma .Oncologist.2010;15(2):168-81.

2. Dwivedi S, Madeshiya A, Singh D, Singh S, Krishna A. Gallbladder cancer and some epidemiological factors: A cross sectional study. Biomedical research.2013; 24(1):83-87.

3. Hundal $\mathrm{R}$ and Shaffer EA. Gallbladder cancer: epidemiology and outcome clinical epidemiology and outcome. Clinical epidemiology.2014;6: 99-109.

4. EngineerR, Wadasadawala T, Mehta S, Mahantshetti U, Purandare N, Rangarajan $\mathrm{V}$ et al. chemoradiation for unresectable gallbladder cancer: time to review historic nihilism. Journal Of Gastrointestinal Cancer.2011;42 (4):222-27.

5. Cho SY, Kim SH, Park JS, Han SS, Kim YK, Lee KW et al. Adjuvant chemoradiation therapy in gallbladder cancer. J. Surg.Oncol.2010;102:87-93.

6. Kang MH, Lee WS, Go S, Kim MJ, Lee US, Choi HJ et al. Can thymidine phosphorylase be a predictive marker for gemcitabine and doxifluridine combination chemotherapy in cholangiocarcinoma?: Case Series. Medicine. 2014;93(28):305.

7. Kapoor R , Singh PK, Bahl A, Kumar R, Kumar N, Gupta R et al. Potential for adjuvant treatment after radical resection in carcinoma gallbladder: a tertiary care experience from india. Clin Cancer Investigation Journal.2013;2:207-11.

8. Malik IA, Aziz Z, Zaidi MSH, Sethuraman G. Gemcitabine and cisplatin 


\section{JMSCR Vol||05||Issue||01||Pages 16058-16064||January}

is a highly effective combination chemotherapy in patients with advanced cancer of the gallbladder. American Journal Of Clinical Oncology.2003;26 (2):174-77.

9. Shewach DS, Lawrence TS. Gemcitabine and radiosensitization in human tumor cells. Invest New Drugs.1996; 14(3):25763.

10. Doval DC, Sekhon JS, Gupta SK, Fuloria I, Shukla VK, Gupta S et al. A Phase II trial of gemcitabine and cisplatin in chemotherapy-naïve, unresectable gallbladder cancer. B J C.2004;90 : 1516-20.

11. Yamashita Y, Taketomi A, Itoh S, Harimoto N, Tsujita E, Sugimachi K et al. Phase II trial of gemcitabine combined with 5-fluorouracil and cisplatin chemotherapy in patients with advanced biliary tree cancer .Jpn J Clin Oncol.2010; 40 (1):24-28.

12. Singh IY, Singh TT and Singh JL. Role of chemoradiation in unresectable gallbladdercarcinoma:5-years

retrospective analysis of RIMS. Journal of Clinical Oncology.2008;26(155):15650.

13. Park JY, Park SW, Chung JB, Seong J, Kim KS, Lee WJ et al. concurrent chemoradiotherapy with doxifluridine and paclitaxel for extrahepatic bile duct cancer. Amj J Cli Onc.2006;29(3):240-45.

14. Gallardo J, Rubio B, Fodon M. A phase II study of gemcitabine in gallbladder cancer. Ann Oncol.2002;12:1403-06.

15. Patt YZ, Hassan MM, Aguayo A . Oral capecitabine for the treatment of hepatocellular carcinoma, cholangiocarcinoma and gallbladder carcinoma. Cancer.2004;101:578-86.

16. Knox JJ , Hedley D, Oza A, Feld R, Siu LL, Chen E, Nematollahi $M$, et al. Combining gemcitabine and capecitabine in patients with advanced biliary cancer : A phase II trial.2005;23(10):2332-38.

17. Common Terminology Ceriteria for Adverse Events (CTCAT) Version 4.0 Published: may 28,2009(June V 4.03:14.2010).National Cancer Institute. 